\title{
Effect of stearic acid on the properties of metronidazole/methocel K4M floating matrices
}

\author{
Belem Lara-Hernández ${ }^{1}$, Alejandra Hernández-León ${ }^{2}$, Leopoldo Villafuerte-Robles ${ }^{\text {* }}$ \\ ${ }^{1}$ Department of Pharmacy, National School of Biological Sciences, National Polytechnic Institute of Mexico, ${ }^{2}$ Department of \\ Biologic Systems, Metropolitan Autonomous University-Xochimilco
}

\begin{abstract}
The properties of metronidazole/Methocel K4M sustained release floating tablets have been studied varying the proportion of the lubricant, stearic acid, on formulations with and without sodium bicarbonate. The variables studied include technological properties of the tablets such as tablet hardness and ejection pressure, the drug release profile, the hydration kinetics and the floating behaviour. The presence of stearic acid and sodium bicarbonate improves the floating behaviour for more than 8 hours. The hydration volume, the tablet hardness and the ejection pressure decrease as the stearic acid content increases and the polymer content decreases. Drug dissolution increases with increasing proportions of stearic acid and decreasing proportions of the polymer in the tablets. The presence of sodium bicarbonate extends the differences in dissolution produced by stearic acid. These results are attributed to decreasing matrices coherence with an increasing quantity of stearic acid and a reducing polymer proportion. The carbon dioxide bubbles produced by sodium bicarbonate expand the matrices facilitating the dissolution, although their presence obstructs also the diffusion path through the hydrated gel layer.
\end{abstract}

Uniterms: Metronidazole. Methocel K4M. Stearic acid. Matrices hydration. Gastric retention. Sodium bicarbonate. Sustained release. Drugs/release mechanism.

Estudaram-se as propriedades de comprimidos flutuantes de metronidazol/Methocel K4M de liberação controlada, variando-se a proporção do lubrificante, ácido esteárico, nas formulações com e sem bicarbonato de sódio. As variáveis estudadas incluem propriedades tecnológicas dos comprimidos, tais como dureza, pressão de ejeção, perfil de liberação do fármaco, cinética de hidratação e comportamento de flutuação. A presença de ácido esteárico e do bicarbonato de sódio melhora o comportamento de flutuação para mais de 8 horas. O volume de hidratação, a dureza e a pressão de ejeção do comprimido decrescem à medida que o conteúdo de ácido esteárico e de polímero diminui. A dissolução do fármaco aumenta com o aumento das proporções de ácido esteárico e a diminuição das proporções de polímero nos comprimidos. A presença de bicarbonato de sódio amplia as diferenças na dissolução produzidas pelo ácido esteárico. Estes resultados são atribuídos à coesão decrescente das matrizes, com o aumento da quantidade de ácido esteárico e a redução da proporção de polímero. Bolhas de dióxido de carbono produzidas pelo bicarbonato de sódio expandem as matrizes, facilitando a dissolução, embora a presença delas obstrua, também, a difusão através da camada de gel hidratado.

Unitermos: Metronidazol. Methocel K4M. Ácido esteárico. Hidratação das matrizes. Retenção gástrica. Bicarbonato de sódio. Fármacos/mecanismo de liberação.

\section{INTRODUCTION}

Drug delivery systems have been designed in more detail with an increasing and better understanding of the

*Correspondence: L. Villafuerte-Robles. Departamento de Farmacia, Escuela Nacional de Ciencias Biológicas, Instituto Politécnico Nacional de México, Carpio y Plan de Ayala s/n, Col. Santo Tomas, C. P. 11340 - Distrito Federal, México.E-mail: lvillaro@encb.ipn.mx physicochemical and biological parameters related to their behaviour in the organism.

Conventional dosage forms are design to provide a given concentration or quantity of the drug in the systemic circulation without any control over drug delivery. Controlled-release drug delivery systems provide drug at a predetermined, predictable and controlled rate. A major constrain in oral controlled drug delivery is that not all 
drug candidates are absorbed uniformly throughout the gastrointestinal tract (GIT). Some drugs are absorbed in a particular portion of the GIT only or are absorbed to a different extent in various segments of the GIT. Such drugs are said to have an absorption window, which identifies the drug's primary region of absorption in the GIT. An absorption window exists because of physiological, physicochemical, or biochemical factors. For instance, the $\mathrm{pH}$-dependent solubility and stability level of a drug plays an important role in its absorption. The drug must be in a solubilised and stable form to successfully cross the biological membrane. They can be enough soluble or stable only in certain parts of the GIT where they can be sufficiently absorbed (Chawla et al., 2003).

Oral sustained release formulations with drugs that are not well absorbed throughout the GIT would be troublesome. From this point of view, some drugs are not amendable to conventional sustained release formulations if they can not be retained in a certain part of the gastrointestinal tract favouring an efficient absorption, for instance, the stomach (Sheth, Tossounian, 1979).

In some cases mucoadhesion has been used in the gastrointestinal tract to increase the residence time in a certain region, in order to improve the systemic absorption or for a local effect (Varum et al., 2008).

Intragastric floating systems have been used pharmaceutically to deliver active substances for sustained release and targeting. Among other, one of the systems that can be used to maintain floating a dosage form in the stomach is that based on a reduction of the matrices density; facilitated by the carbon dioxide resulting from the reaction of sodium bicarbonate with an acidic medium like that of the stomach (Xu, Groves, 2001; Jiménez-Martínez et al., 2008; Sriamornsak et al., 2007).

Although some other attempts have been made to provide a dosage form with a longer gastrointestinal transit time, floating delivery systems seem to offer a greater safety for clinical uses than some other approaches (Li et al., 2002). Gastric floating drug delivery systems are able to prolong the stomach retention time of a dosage form, thereby improving the local activity, the stability and the absorption of the drugs (Li et al., 2001).

Hydrophilic polymers are actually one of the most used excipients to control drug delivery from an oral pharmaceutical dosage form. Hydroxypropyl methylcellulose (HPMC) is a polymer often used in the formulation of pharmaceutical sustained dosage forms. The mechanisms by which it retards drug release include its ability to form rapidly a gel layer at the matrix periphery exposed to aqueous fluids (Mandal, 1995). The drug is released from the matrix mainly by diffusion through water filled pores.
Consequently, the release rate is associated to porosity and tortuosity of the pores and channels network. The porosity and tortuosity of a swellable matrix is primarily attributed to the swelling ability of the polymer (Efentakis et al., 1997).

In spite of the good properties of cellulose derivatives to move smoothly over the inner surfaces of the dies where the tablets are compacted, some other formulation excipients and drugs can make necessary the use of lubricants to assure a smooth fabrication on the production lines. Stearic acid is widely used in oral pharmaceutical formulations. It is mainly used in oral formulations as a tablet lubricant although it may also be used as a binder (Kibbe, 2000).

Stearic acid has been used for the controlled release as a dispersion medium of drugs in the form of microspheres made of fats and waxes. The microspheres are obtained by the spray and congealing method. Mixtures of diclofenac with greasy materials such as glyceryl monostearate decrease their dissolution rate as the proportion of the greasy material in the formulation increases. Contrasting, stearic acid seems to permit channelling of the drug from the glyceryl monostearate matrix. In this type of controlled release formulations a polymeric material such as polyvinylpyrrolidone (PVP) has been used as a dispersion medium. The increase of the proportion of the dispersing agent (PVP) produced an increase of the release rate of the drug (Vilivalam, Adeyeye, 1994).

In a similar experimental design, stearic acid has been used with hydrophilic excipients to obtain felodipine microparticles by the spray and congealing method. In this particular case, the effect of the hydrophilic excipients was considered of no consequence. The felodipine dissolution from matrices containing $50 \%$ or more stearic acid attained $20 \%$ after 7 hours (Savolainen, 2003).

Stearic acid has been also used as a binder and vehicle for the controlled release formulation of theophiline. It has been used to control the dissolution rate of cylindrical dosage forms obtained by extrusion (Grassi et al., 2003).

Theophiline release from tablets made of a mixture of hydrophobic granules (one third of stearic acid) and granules of a hydrophilic polymer (HPMC) shows that the dissolution rate decreases progressively as the hydrophobic portion of the mixture increases from $10 \%$ to $90 \%$ of the total weight of the tablets (Hayashi, 2005).

Metronidazole has been selected as a model drug for floating tablets with a probable gastric retention, because of a general assent about the benefits of eradication of $H$. pylori in patients with peptic ulcer. The treatments include antibacterials such as bismuth salts, amoxicillin, macrolides, tetracycline and nitroimidazoles such as me- 
tronidazole and tinidazole (González et al., 2001). Drugs administered systemically are absorbed into the blood stream and distributed throughout the host patient via the circulatory system, which can result in bacterial resistance. When administered locally, they limit the adverse effects of systemic administration and there is a higher concentration of medication reaching the targeted site (Namazi, Kanani, 2009).

The aim of the study is to examine the effect of stearic acid and sodium bicarbonate on the hydration and floatation behaviour, on the tableting properties as well as on the release profile of Methocel K4M matrices, using metronidazole as a model drug. The results will increase the actual knowledge about the goodness of this type of formulations for their processing as tablets.

\section{MATERIALS AND METHODS}

\section{Materials}

The pharmaceutical excipients Methocel K4M, hydroxypropyl methylcellulose supplied by the Dow Chemical company, and the stearic acid and the drug metronidazole obtained from Química Alkano Mexico, were used as received. The sodium bicarbonate was analytical grade from J. T. Baker-Mexico.

\section{Matrix preparation}

As a previous step of the matrix preparation, the drug was pulverized $1 \mathrm{~min}$. using an analytical mill at 20000 rpm (Tekmar A-10, Janke and Kunkel GmbH, Germany). The sodium bicarbonate was size reduced in a mortar for $10 \mathrm{~min}$. Stearic acid was sifted through a number 30 sieve before it was used. The use of sodium bicarbonate is recommended at a relative humidity below $80 \%$, to avoid decomposition (Kibbe, 2000). In this case, the matrices were always kept in two polyethylene bags, only as a precaution. The laboratory shows a relative humidity fluctuating between $38 \%$ and $65 \%$.

Initially, matrix tablets were produced by using $150 \mathrm{mg}$ metronidazole and $450 \mathrm{mg}$ Methocel K4M, for a total matrix weight of $600 \mathrm{mg}$. In this series of matrix tablets different quantities of the polymer content were substituted by stearic acid: 50, 100 y $150 \mathrm{mg}$ per tablet, keeping the total tablet weight at $600 \mathrm{mg}$ per tablet.

In a second series of matrix tablets $54 \mathrm{mg}$ of the polymer content were substituted by sodium bicarbonate. The matrices were prepared with the same above mentioned proportions of metronidazole and stearic acid.

Metronidazole, the polymer and sodium bicarbonate corresponding to 20 tablets were mixed for $20 \mathrm{~min}$. Thereafter, the stearic acid was added and the mixing continued for $10 \mathrm{~min}$. Tablets were compressed in a hydraulic press fitted with flat faced $12.5 \mathrm{~mm}$ punch and die sets at a pressure of $55 \mathrm{MPa}$ during 10 seconds.

\section{Compaction characteristics of the tablets}

The tablets ejection pressure was determined following their compaction, measuring the pressure necessary to eject the tablet from the die where it was compressed. The measurement was accomplished with hydraulic presses of different capacities added with manometers with red pointer.

The tablet hardness was measured using hydraulic presses similar to that above mentioned and was expressed as the pressure needed to fracture the tablets diametrically.

\section{Matrices hydration and floating time}

Swelling was ascertained by measuring the axial and radial expansion of matrix tablets following exposure to dissolution medium. The dimensions of each matrix were measured using a dial caliper (General Tools, New York) prior to dissolution studies. Tablet hydration tests were performed using the same conditions described in the dissolution studies. At various time intervals the tablets were removed from the dissolution medium and measured in their dimensions using a microscope with digital camera (National Optical \& Scientific Instruments, USA). The tablet volume was calculated considering a right circular cylinder form. The results for each time point of three repetitions are registered as an average.

The floating time was determined by observation of the floating behaviour throughout the dissolution studies and was registered as the average of 3 repetitions.

\section{Drug release}

Release data from swellable systems can be analyzed according to the power law expression shown in equation 1. The kinetics and mechanism of drug release for each system was investigated by fitting the release data into this equation (Rinaki et al., 2003).

$$
\mathrm{M}_{\mathrm{t}} / \mathrm{M}_{\mathrm{inf}}=k * t^{n} \text { or } \ln \left(\mathrm{M}_{\mathrm{t}} / \mathrm{M}_{\mathrm{inf}}\right)=n * \ln (t)+\ln (k)
$$

The terms in this equation are as follows: $M_{t}$, the amount of drug released at time $t ; \mathrm{M}_{\text {inf }}$, the total drug released over a long time period; $k$, the kinetics constant; and $n$, the mechanism of drug release. The value of $n$ ranges 
from $0.5\left(t^{1 / 2}\right.$ dependence, generally referred to as Fickian release) to 1 (representing the case II transport which is purely relaxation controlled). The values in between indicate an anomalous behaviour corresponding to coupled diffusion/relaxation. When the value of $n$ is greater than that of the case-II transport $(n>1.0)$, the release is said to be Super case-II transport (Brazel, Peppas, 2000; Ranga Rao et al., 1988). In the case of a matrix with cylinder form, $n$ is said to be 0.45 instead of 0.5 and 0.89 instead of 1.0 (Kim, Fassihi, 1997).

Dissolution studies were performed in $900 \mathrm{ml}$ of $\mathrm{HCl}$ $0.1 \mathrm{~N}$ using the paddle method (USP 26), at $50 \mathrm{rpm}$ and $37^{\circ} \mathrm{C}$ (JT R09, TEMSA, Mexico). The amount of metronidazole released over time was determined by withdrawing samples at various time intervals. The concentration of metronidazole was obtained by measuring its absorbance at $276 \mathrm{~nm}$ in a Beckman DU-650 ultraviolet spectrophotometer.

The results for each time point of three different dissolution curves are registered as an average in the figures. These average values were used to calculate the regression parameters of each dissolution curve representing a given formula.

\section{RESULTS AND DISCUSSION}

\section{Matrices floating time}

Matrices made of Methocel K4M and stearic acid float more than 8 hours (Table I) while matrices without stearic acid float only 6 hours. The matrices floatability is attributed to the intrinsic Methocel properties and to a reduction of density produced by elevated quantities of the stearic acid which displays a true density of $0.980 \mathrm{~g} / \mathrm{cm}^{3}$. The addition of $54 \mathrm{mg}$ of sodium bicarbonate per tablet allowed in all cases floating times greater than 8 hours (Table II).

The matrices behaviour is attributed to a relative rapid hydration of the external surface area of the Methocel K4M matrices, keeping for a longer time the original air bubbles that remain in the matrix after compression. The carbon dioxide bubbles, obtained after addition of sodium bicarbonate and its reaction with the acidic dissolution medium, produce a reinforcement of the matrix floatability. The carbon dioxide bubbles show a trend to disappear progressively with time as the matrix hydration progresses. However, the rapid gel formation on the matrices surface area contacting the dissolution medium reduces the speed of the bubbles disappearing through the gel layer.

\section{Compaction characteristics of the tablets}

With the aim to establish a confident method to produce tablets it is convenient to examine the effect of addition of different proportions of the lubricant to metronidazole formulations, to reduce their adhesiveness to compaction tools. Although the usual proportions of the lubricant used in tablet formulation is in the range of $0.5-2.0 \%$, in this case higher proportions were used with the purpose to observe its potential obstruction effect on the metronidazole dissolu-

TABLE I - Characteristics of Methocel K4M matrices containing $150 \mathrm{mg}$ metronidazole and different proportions of stearic acid for a total matrix weight of $600 \mathrm{mg}$; compacted at $55 \mathrm{MPa}$

\begin{tabular}{lcccc}
\hline $\begin{array}{l}\text { Stearic acid } \\
(\mathrm{mg} / \text { tablet })\end{array}$ & $\begin{array}{c}\text { Pexp } \\
(\mathrm{MPa})\end{array}$ & $\begin{array}{c}\text { Tablet hardness } \\
(\mathrm{MPa})\end{array}$ & $\begin{array}{c}\text { Floating time } \\
(\mathrm{min})\end{array}$ & $\begin{array}{c}\text { Vmax } \\
\left(\mathrm{mm}^{3}\right)\end{array}$ \\
\hline 0 & 2.79 & 1.94 & 360 & 1894 \\
50 & 1.17 & 1.16 & $>480$ & 1861 \\
100 & 1.00 & 1.80 & $>480$ & 1819 \\
150 & 1.02 & 0.86 & $>480$ & 1469 \\
\hline
\end{tabular}

Abbreviations: Pexp = Ejection pressure of the tablets; Vmax = Maximal hydration volume reached by matrices .

TABLE II - Characteristics of Methocel K4M matrices containing $150 \mathrm{mg}$ metronidazole, $54 \mathrm{mg}$ sodium bicarbonate and different proportions of stearic acid for a total matrix weight of $600 \mathrm{mg}$; compacted at $55 \mathrm{MPa}$

\begin{tabular}{lcccc}
\hline $\begin{array}{l}\text { Stearic acid } \\
(\mathrm{mg} / \text { tablet })\end{array}$ & $\begin{array}{c}\text { Pexp } \\
(\mathrm{MPa})\end{array}$ & $\begin{array}{c}\text { Tablet hardness } \\
(\mathrm{MPa})\end{array}$ & $\begin{array}{c}\text { Floating time } \\
(\mathrm{min})\end{array}$ & $\begin{array}{c}\text { Vmax } \\
\left(\mathrm{mm}^{3}\right)\end{array}$ \\
\hline 0 & 1.55 & 1.42 & $>480$ & 1980 \\
50 & 1.34 & 1.34 & $>480$ & 1895 \\
100 & 1.86 & 0.78 & $>480$ & 2016 \\
150 & 1.22 & 0.79 & $>480$ & 1515 \\
\hline
\end{tabular}

Abbreviations: Pexp = Ejection pressure of the tablets; Vmax = Maximal hydration volume reached by matrices . 


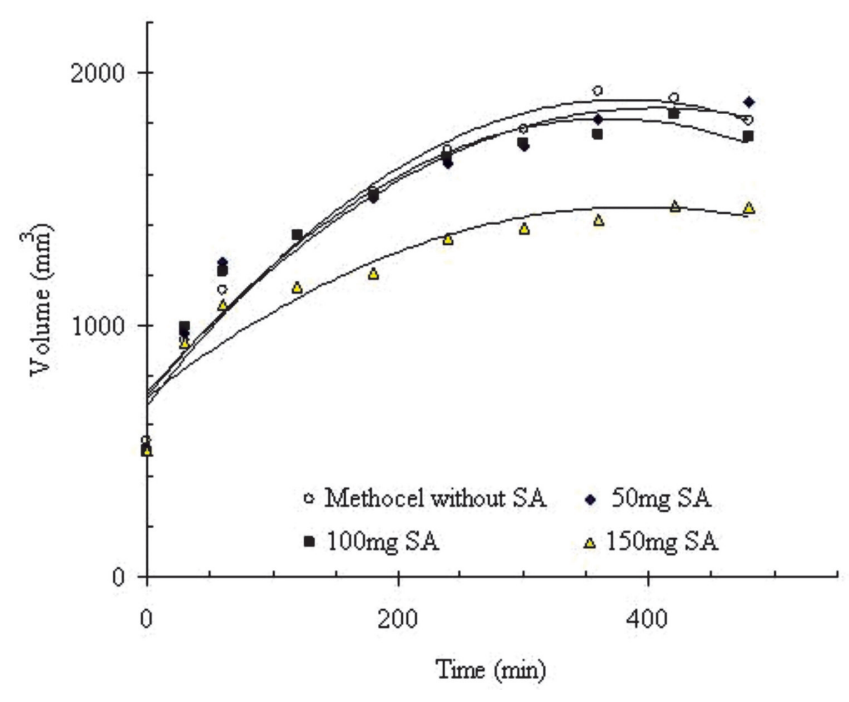

FIGURE 1 - Hydration kinetics of matrices containing $150 \mathrm{mg}$ metronidazole and variable quantities of Methocel K4M and stearic acid (SA), for a total matrix weight of $600 \mathrm{mg}$.

tion. This was studied as an additional effect of its properties to overcome the adhesive forces between the compaction tools and the matrix tablets (Kranz, Wagner, 2006). As can be seen in Tables I and II, the ejection pressure of Methocel matrices decreases progressively as the proportion of stearic acid in the formulation increases.

As expected from cellulose derivatives, the addition of stearic acid reduces the tablet hardness practically in the same proportion as it reduces the ejection pressure. However, in spite of a reduction of the tablet hardness up to $50 \%$, the tablets are considered strong enough to permit their manipulation without problems.

\section{Matrices hydration}

Hydrophilic matrices immersed in water swell and eventually dissolve. When they are placed in water, swelling starts and the tablet thickness increases. Initially, water only diffuses through the polymeric matrix. As the polymer chains become more hydrated and the gel becomes more diluted the disentanglement concentration may be reached and the polymer chains detach from a gellified matrix. Thus, there is a slow diminution of the matrix thickness due to polymer dissolution. The polymer in the matrix undergoes simultaneously swelling, dissolution and diffusion into the bulk medium, resulting in reduction of strength and erosion of the matrix (Shott, 1992; Katzhendler et al., 1997; Kavanagh, Corrigan 2004).

As can be seen in Figures 1 and 2, the matrices hydration volume increases rapidly at the beginning, reaches a

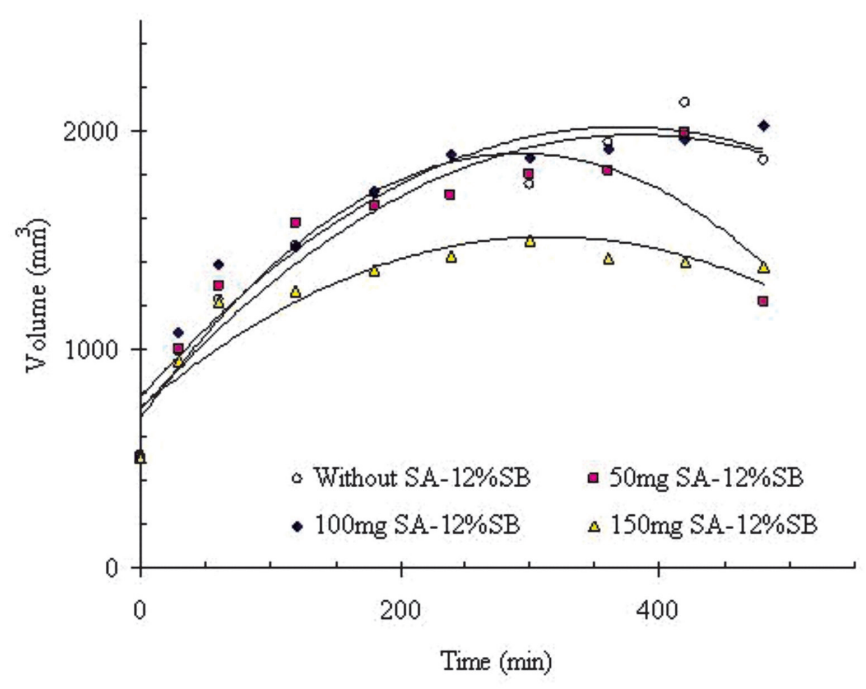

FIGURE 2 - Hydration kinetics of matrices containing metronidazole $(150 \mathrm{mg})$, sodium bicarbonate (SB) $(54 \mathrm{mg})$ and variable quantities of Methocel K4M and stearic acid (SA) for a total matrix weight of $600 \mathrm{mg}$.

maximum, and then decline. While the polymer swelling progresses toward higher matrix volumes, the polymer dissolution produces the opposite.

The addition of stearic acid to metronidazole/Methocel matrices, with and without sodium bicarbonate, reduces the hydration volume. This is attributed to a lessening of the polymer proportion due to its partial substitution with stearic acid.

The addition of sodium bicarbonate to Methocel matrices expands their volume due to gas bubbles formed after its reaction with the acidic dissolution medium. The average maximal volume reached by matrices with sodium bicarbonate during hydration $\left(1851 \mathrm{~mm}^{3}\right)$ is only to some extent greater than that reached by matrices without it $\left(1760 \mathrm{~mm}^{3}\right)$. However, it has to be considered that the addition of sodium bicarbonate means a reduction in the same magnitude in the polymer content, decreasing the matrices swelling capability. The decrease in the polymer content is compensated by an expansion produced by the carbon dioxide bubbles. Moreover, the decrease of the swelling polymer as well as a minor consistency of matrices containing bicarbonate facilitates the matrix erosion. It is considered that the gas bubbles dissipating from the inside to the outside of the matrix debilitates the matrix structure.

\section{Release of metronidazole from Methocel K4M matrices}

Release profiles of metronidazole from Methocel K4M matrices containing different proportions of stearic acid, fitting dissolution data into equation 1 , produced 
TABLE III - Regression parameters and the standard error (s. e.) of release profiles of metronidazole (150 mg) from Methocel K4M matrices containing different proportions of stearic acid, for a total matrix weight of $600 \mathrm{mg} / \mathrm{tablet}$

\begin{tabular}{lccccc}
\hline $\begin{array}{l}\text { Stearic acid } \\
(\mathrm{mg} / \text { tablet })\end{array}$ & $\begin{array}{c}\mathrm{k} \\
( \pm \mathrm{s} . \mathrm{e} .)\end{array}$ & $\begin{array}{c}\mathrm{n} \\
( \pm \mathrm{e} . \mathrm{t} .)\end{array}$ & $\begin{array}{c}\text { Metro-8h } \\
(\%)\end{array}$ & $\begin{array}{c}\text { Metro-6h } \\
(\%)\end{array}$ & $\mathrm{r}^{2}$ \\
\hline 0 & $3.644 \pm 1.0886$ & $0.5366 \pm 0.0156$ & 66.7 & 57.2 & 0.995 \\
50 & $2.475 \pm 1.0569$ & $0.6112 \pm 0.0113$ & 71.8 & 60.2 & 0.998 \\
100 & $4.593 \pm 1.0717$ & $0.5068 \pm 0.0131$ & 69.9 & 60.5 & 0.995 \\
150 & $5.340 \pm 1.0891$ & $0.4850 \pm 0.0162$ & 71.1 & 61.8 & 0.992 \\
\hline
\end{tabular}

Abbreviations: $\mathrm{k}=$ Kinetics or release constant; $\mathrm{n}=$ exponent indicative of the release mechanism; Metro- $8 \mathrm{~h}(6 \mathrm{~h})=$ calculated metronidazole dissolution after 8 hours (6 hours).

TABLE IV - Regression parameters and the standard error (s.e.) of release profiles of metronidazole (150 mg) from Methocel K4M matrices containing $54 \mathrm{mg}$ sodium bicarbonate and different proportions of stearic acid, for a total matrix weight of $600 \mathrm{mg} / \mathrm{tablet}$

\begin{tabular}{lccccc}
\hline $\begin{array}{l}\text { Stearic acid } \\
(\mathrm{mg} / \text { tablet })\end{array}$ & $\begin{array}{c}\mathrm{k} \\
( \pm \text { e. t.) }\end{array}$ & $\begin{array}{c}\mathrm{n} \\
( \pm \text { e. t. })\end{array}$ & $\begin{array}{c}\text { Metro-8h } \\
(\%)\end{array}$ & $\begin{array}{c}\text { Metro-6h } \\
(\%)\end{array}$ & $\mathrm{r}^{2}$ \\
\hline 0 & $5.182 \pm 1.136$ & $0.4601 \pm 0.0241$ & 59.2 & 51.8 & 0.981 \\
50 & $3.013 \pm 1.103$ & $0.5276 \pm 0.0187$ & 52.2 & 44.8 & 0.991 \\
100 & $3.524 \pm 1,182$ & $0.5183 \pm 0.0318$ & 57.6 & 49.6 & 0.974 \\
150 & $7.946 \pm 1.149$ & $0.4258 \pm 0.0264$ & 73.4 & 64.9 & 0.974 \\
\hline
\end{tabular}

Abbreviations: $\mathrm{k}=$ Kinetics or release constant; $\mathrm{n}=$ exponent indicative of the release mechanism; Metro-8h $(6 \mathrm{~h})=$ calculated metronidazole dissolution after 8 hours (6 hours).

straight lines for data corresponding to drug release up to 8 hours (Figures 3 and 4). The regression parameters obtained with equation 1 are registered in Tables III and IV. The effect of addition of lubricants such as stearic acid is expected to produce a lessening of drug dissolution as the proportion of the lubricant increases (Kranz, Wagner, 2006). However, here occurs the opposite. The effect of lessening the drug release with an increasing lubricant proportion, in a range of $0.5-2.0 \%$, can be ascribed to an increase of the hydrophobic nature of the matrix. On the other hand, the opposite effect of the same lubricant, at higher proportions $(<25 \%)$, can be attributed to a decreased matrix coherence. This loss of coherence can be ascribed to a partial obstruction of the interparticle binding sites of the polymer particles giving shape to the matrix. Moreover, this can also be ascribed to a lesser polymer proportion, after it was substituted by greater lubricant proportions.

Although the differences observed by the different release profiles of matrices without bicarbonate are small (Figure 3), it is observed a clear trend toward greater quantities of metronidazole dissolved as the stearic acid content of these matrices moves up. This trend is more noticeable in matrices containing sodium bicarbonate (Figure 4). Regardless of a greater dispersion of the dissolution data from matrices containing sodium bicarbonate, the avera- ge standard error of $\mathrm{k}$ is $1.142 \pm 0.033$ compared to 1.077 \pm 0.014 displayed by matrices without bicarbonate, this dispersion degree do not hide from view the effect of the carbon dioxide produced by sodium bicarbonate.

At low proportions of stearic acid, it is observed a lessening of the metronidazole dissolved, ascribed to an

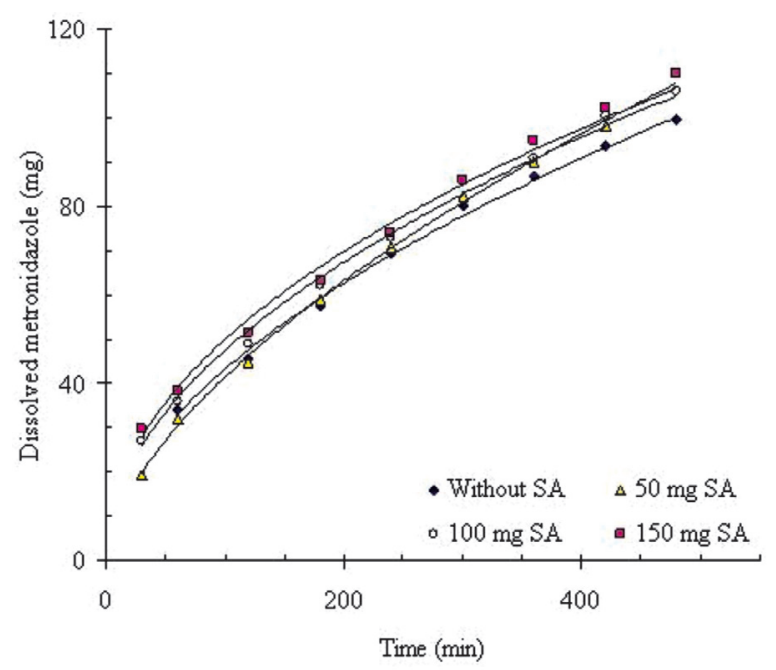

FIGURE 3 - Release profiles of metronidazole $(150 \mathrm{mg}$ ) from matrices containing variable quantities of stearic acid (SA) and Methocel K4M for a total matrix weight of $600 \mathrm{mg}$. 


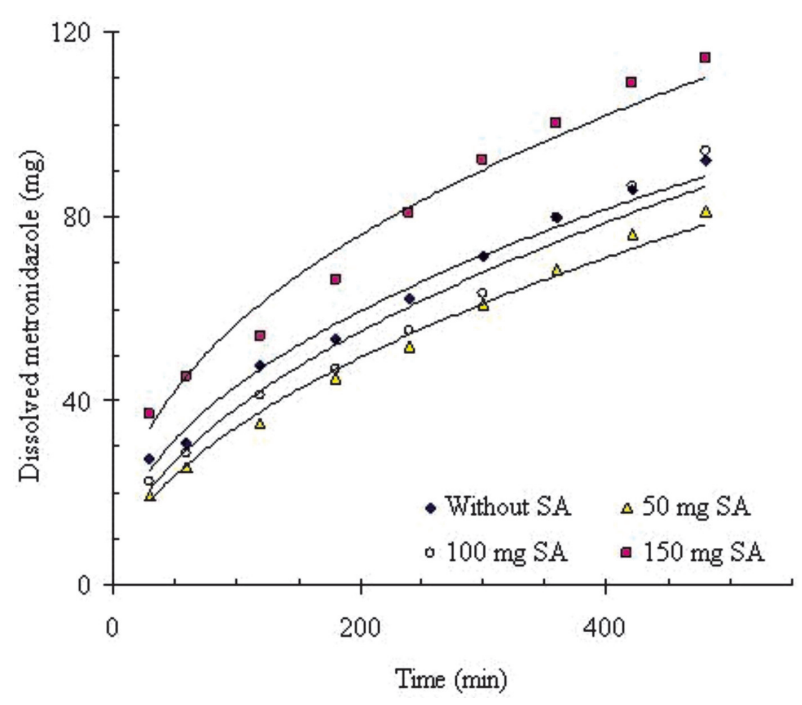

FIGURE 4 - Release profiles of metronidazole $(150 \mathrm{mg})$ from matrices containing $54 \mathrm{mg}$ sodium bicarbonate $(\mathrm{SB})$ and variable quantities of stearic acid (SA) and Methocel K4M for a total matrix weight of $600 \mathrm{mg}$.

increase in the hydrophobic nature of the matrix. However, at higher proportions of the lubricant an effect of obstruction of the interparticle bonds of the polymer particles giving shape to the matrix prevails over the above mentioned effect. This produces an increase of the dissolution rate of metronidazole.

On the other hand, matrices containing sodium bicarbonate show expanded differences in the release profiles. The presence of sodium bicarbonate, at low proportions of stearic acid, reduces the release rate of the drug while at higher proportions of stearic acid it increases.

The above mentioned can be explained because of a partial obstruction of the diffusion path caused by the carbon dioxide bubbles dispersed in the matrix. The presence of the gas bubbles slows down the water transport in the direction of the matrix as well as the transport of the dissolved metronidazole towards the outside of the matrix. However, the matrix expansion effect caused by the same bubbles debilitates the matrix structure, increasing its volume. This allows a recovery and increase of the drug dissolution in matrices containing $150 \mathrm{mg}$ stearic acid. The expansion of the matrix produced by carbon dioxide makes evident the reduction of the matrix coherence produced by stearic acid. This means, the carbon dioxide bubbles make more evident the strength or the weakness of a matrix, produced by the presence of stearic acid.

Figures 5 and 6 show the increase of the release constant values after addition of stearic acid. The predominant effect of stearic acid would be that of obstruction of the interparticles bonds of the polymer particles, decreasing the matrix coherence and facilitating the matrix expansion from the very beginning. All this contributes to increase the drug dissolution. In the same way, the figures also show decreasing values of the exponent indicative of the release mechanism of metronidazole as the proportion of stearic acid increases. The last statement can be explained in terms of the possibilities for relaxation or expansion of these matrices. A matrix with a high proportion of stearic acid, having a lower coherence, relaxes faster. Because of this, its capability to relax further with time is lesser. A matrix that relaxes slowly release the drug basically by diffusion through the water filled pores. This circumstance is expressed as lower values of the exponent indicative of the release mechanism (n). Then again, a matrix with a lower proportion of stearic acid displays a greater coherence due to a greater binding surface area of the polymer particles one with each other. This greater matrix coherence permits only a lesser relaxation or swelling speed. The swelling and relaxation processes take a longer time, increasing gradually the volume of the water filled pores and with this, increase the drug release rate. This circumstance is expressed as greater values of the exponent (n). This points out to a release mechanism moving gradually from a mechanism predominantly controlled by diffusion towards a mechanism with a greater contribution of the matrix relaxation process.

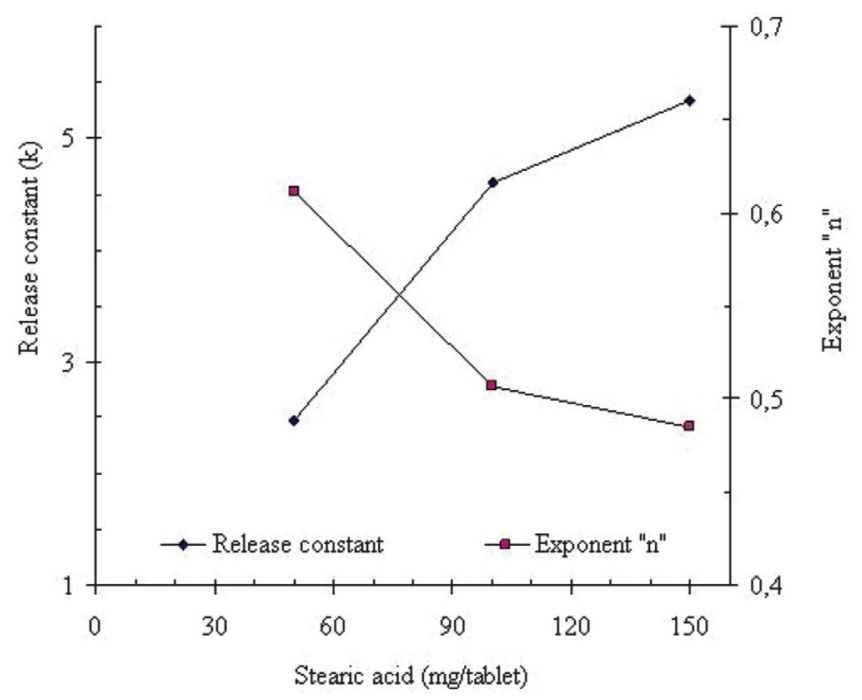

FIGURE 5 - Effect of stearic acid on the regression parameters of metronidazole $(150 \mathrm{mg}$ ) release profiles from Methocel K4M matrices with a total weight of $600 \mathrm{mg}$.

The swelling of the polymer particles produces an expansion that sources a more noticeable matrix relaxation when the polymer particles are strongly bonded. Weak or less strong interparticles bonds, for instance produced by greater proportions of a lubricant, favour a less coherent structure 


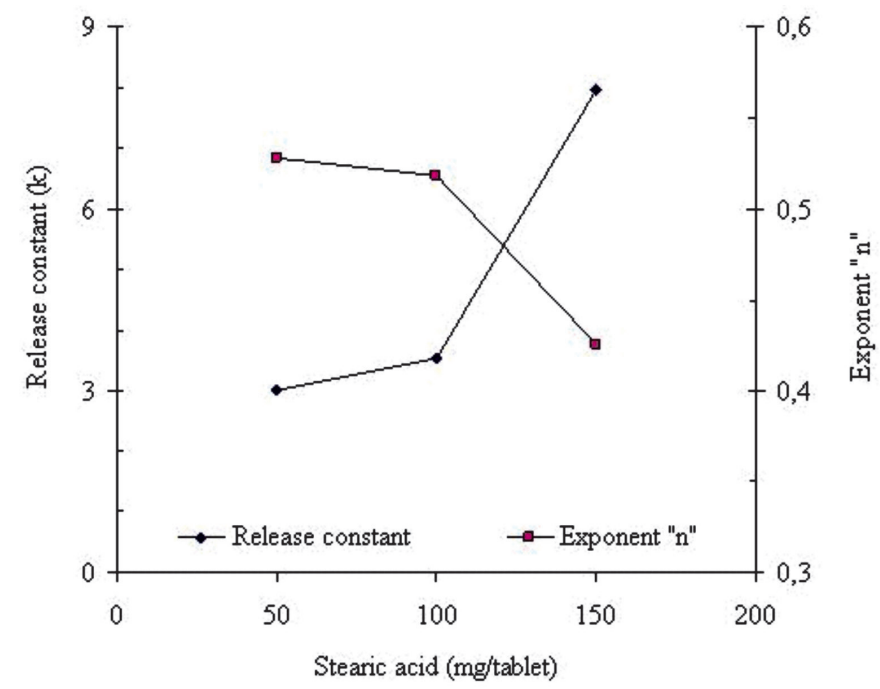

FIGURE 6 - Effect of stearic acid on the regression parameters of metronidazole $(150 \mathrm{mg}$ ) release profiles from matrices containing $54 \mathrm{mg}$ sodium bicarbonate and Methocel K4M for a total matrix weight of $600 \mathrm{mg}$.

from the very beginning. In this sense, a further relaxation because of polymer swelling is less noticeable. Matrices with lower stearic acid proportions display a release mechanism with a greater contribution of matrix relaxation, compared to matrices containing greater lubricant proportions.

\section{CONCLUSION}

Although Methocel is not a polymer showing a strong adhesion to compaction tools some other components of a formulation can make necessary the addition of a lubricant to smooth the progress of the fabrication process. Stearic acid is used to reduce the tablet ejection pressure up to a reasonable level for production, despite the fact that it also reduces the tablet hardness. Even so, it is considered that the tablet hardness can be still satisfactory to manipulate the matrix tablets without problems or physical deterioration.

The matrices hydration kinetics shows a quadratic relationship with respect to time. This relationship is attributed to a simultaneous matrix swelling and erosion. Initially, it is observed an increase of hydration volume, reaching a maximum that declines thereafter. The matrices hydration volume is directly related to the matrix polymer proportion. It means that a decrease of the polymeric phase, as a consequence of its substitution by stearic acid, corresponds to a reduction of the matrix hydration volume. The addition of sodium bicarbonate, with the corresponding reduction of the polymeric phase, may well be associated with a reduction of the hydration volume. However, this is not the case. There is a recovery and eventually an increase of the hydration volu- me as a consequence of a matrix expansion produced by the generation of gas bubbles in the hydrated gel layer.

With respect of the method used to determine the ejection pressure, the tablet hardness and the hydration volume, they have to be improved to get a better confidence level on the obtained results.

The floating properties of hydrophilic matrices depend first of all of the intrinsic properties of the polymer, properties that can be modified with some other added excipients. The characteristic of Methocel to form rapidly a gel layer on the matrix surface area contacting an aqueous medium allows the preservation or the delay of the dissipation of the original air bubbles or the created carbon dioxide bubbles. This makes possible the matrices floatation.

Stearic acid behaves as an inert material that modifies the metronidazole dissolution. Metronidazole dissolution increases with increasing proportions of stearic acid, associated to decreasing proportions of the matrix polymer content. This effect seems to be related to a reduction of the dissolution restricting phase, the polymeric material, and to the obstruction of the interparticle bonds of the polymeric phase. The presence of sodium bicarbonate produces carbon dioxide bubbles. These bubbles obstruct the transport throughout the matrix, reducing the drug dissolution rate, in spite of a lesser proportion of the polymeric phase. However, these bubbles also enlarge the matrix volume, allowing an increase in the drug release rate.

\section{REFERENCES}

BRAZEL, C. S., PEPPAS, N. A. Modelling of drug release from swellable polymers. Eur. J. Pharm. Biopharm., v.49, n.1, p.47-58, 2000.

CHAWLA, G., GUPTA, P., KORADIA, V., BANSAL, A. K. A means to address regional variability in intestinal drug absorption. Pharm. Tech., July, p.50-68, 2003. Available at: $<$ http://search.findpharma.com/search?qgeneral=Cha wla\&searchtype $=c 140 \_p 532$ s894_s973>. Accessed on: $3^{\text {rd }}$ jun. 2009.

EFENTAKIS, M., VLACHOU, M., CHOULIS, N. H. Effects of excipients on swelling and drug release from compressed matrices. Drug Dev. Ind. Pharm., v.23, n.1, p.107-112, 1997.

GONZÁLES, C., GARCÍA, A., DAROCH, F., KAWAGUCHI, F., SOLAR, H., RIVERA, N., VEGA, E. Susceptibilidad in vitro de cepas de Helicobacter pylori: aislamiento de cepas resistentes a claritromicina. Rev. Méd. Chile, v.129, n.6, p.643-646, 2001. 
GRASSI, M., VOINOVICH, D., FRANCESCHINIS, E., PERISSUTTI, B., FILIPOVIC-GRCIC, J. J. Theoretical and experimental study on theophylline release from stearic acid cylindrical delivery systems. J. Control. Release, v.92, n.3, p.275-289, 2003.

HAYASHI, Y., KANBE, H., OKADA, M., SUSUKI, M., IKEDA, Y., ONUKI, Y., KANEKO, T., SONOBE, T. Formulation study and release mechanism of a new theophylline sustained-release preparation. Int. J. Pharm., v.304, n.1-2, p.91-101, 2005.

JIMÉNEZ-MARTÍNEZ, I., QUIRINO-BARREDA, T., VILLAFUERTE-ROBLES, L. Sustained delivery of captopril from floating matrix tablets. Int. J. Pharm., v.62, n.1-2, p.37-43, 2008.

KATZHENDLER, I., HOFFMAN, A., GOLDBERGER, A., FRIEDMAN, M. Modelling of drug release from erodible tablets. J. Pharm. Sci., v.86, n.1, p.110-115, 1997.

KAVANAGH, N., CORRIGAN, O. I. Swelling and erosion properties of hydroxypropylmethylcellulose (Hypromellose) matrices - influence of agitation and dissolution medium composition. Int. J. Pharm., v.279, n.1-2, p.141-152, 2004.

KIM, H., FASSIHI, R., Application of binary polymer system in drug release rate modulation. 2. Influence of formulation variables and hydrodynamic conditions on release kinetics. J. Pharm. Sci., v.86, n.3, p.323-328, 1997.

KIBBE A. H. (Ed.). Handbook of pharmaceutical excipients. 3.ed. Washington: American Pharmaceutical Association, 2000. p.534-536.

KRANZ, H., WAGNER, T. Effects of formulation and process variables on the release of a weakly basic drug from single unit extended release formulations. Eur. J. Pharm. Biopharm., v.62, n.1, p.70-76, 2006.

LI, S., LIN, S., CHIEN, Y. W., DAGGY, B. P., MIRCHANDANI, H. L. Statistical optimization of gastric floating system for oral controlled delivery of calcium. AAPS PharmSciTech, v.2, n.1, article 1, 2001. Available at: <http://www. aapspharmscitech.org/articles/pt0201/pt020101/pt020101. pdf $>$. Accessed on: $3^{\text {rd }}$ jun. 2009.

LI. S., LIN, S., DAGGY, B. P., MARCHANDANI, H. L., CHIEN, Y. W. Effect of formulation variables on the floating properties of gastric floating drug delivery system. Drug Dev. Ind. Pharm., v.28, n.7, p.783-793, 2002.
MANDAL, T. K. The influence of binding solvents on drug release from hydroxypropyl methylcellulose tablets. Drug Dev. Ind. Pharm., v.21, n.12, p.1389-21397, 1995.

NAMAZI, H., KANANI, A. Investigation diffusion mechanism of $\beta$-lactam conjugated telechelic polymers of PEG and $\beta$-cyclodextrin as the new nanosized drug carrier devices. Carbohydr. Polym., v.76, n.1, p.46-50, 2009.

RINAKI, E., VALSAMI, G., MACHERAS P. The power law can describe the "entire" drug release curve from HPMCbased matrix tablets: a hypothesis. Int. J. Pharm., v.255, n.1-2, p.199-207, 2003.

RANGA RAO, K.V., PADMALATHA DEVI, K., BURI P., Cellulose matrices for zero-order release of soluble drugs. Drug Dev. Ind. Pharm., v.14, n.15-17, p.2299-2320, 1988.

SAVOLAINEN, M., HERDER, J., KHOO, C., LÖVQVIST, K., DAHLQVIST, K., GOLAD, H., JUPPO, A. M. Evaluation of polar lipid-hydrophilic polymer microparticles. Int. J. Pharm., v.262, n.1-2, p.47-62, 2003.

SHETH, P. R.; TOSSOUNIAN, J. L. United States patent 4, 140, 755. Sustained release formulations, 1979. p.1-2.

SHOTT, H. Kinetics of swelling of polymers and their gels. $J$. Pharm. Sci., v.81, n.5, p.467-470, 1992.

S R I A MORN S A K, P., SUNGTHONGJEEN, S., PUTTIPIPATKHACHORN, S., Use of pectin as a carrier for intragastric floating drug delivery: Carbonate salt contained beads. Carbohydr. Polym., v.67, n.3, p.436-445, 2007.

VARUM, F. O., BASIT, A. W., SOUSA, J., VEIGA, F. Estudos de mucoadesão no trato gastrointestinal para o aumento da biodisponibilidade oral de fármacos. Rev. Bras. Cienc. Farm., v.44, n.4, p.535-548, 2008.

VILIVALAM, V. D., ADEYEYE, C. M. Development and evaluation of controlled-release diclofenac microspheres and tableted microspheres. J. Microencapsul., v.11, n.4, p.445-470, 1994.

XU, G., GROVES, M. J. Effect of FITC-dextran molecular weight on its release from floating cetyl alcohol and HPMC tablets. J. Pharm. Pharmacol., v.53, n.1, p.49-55, 2001.

Received for publication on $16^{\text {th }}$ July 2007 Accepted for publication on $22^{\text {th }}$ May 2009 